\title{
BRCA1 haploinsufficiency cell-autonomously activates RANKL expression and generates denosumab-responsive breast cancer- initiating cells
}

\author{
Elisabet Cuyàs ${ }^{1,2}$, Bruna Corominas-Faja1,2, María Muñoz-San Martín ${ }^{3}$, Begoña \\ Martin-Castillo ${ }^{2,4}$, Ruth Lupu ${ }^{5,6}$, Joan Brunet ${ }^{7,8}$, Joaquim Bosch-Barrera7,8 and \\ Javier A. Menendez ${ }^{1,2}$ \\ ${ }^{1}$ Program Against Cancer Therapeutic Resistance (ProCURE), Metabolism and Cancer Group, Catalan Institute of Oncology, \\ Girona, Catalonia, Spain \\ ${ }^{2}$ Molecular Oncology Group, Girona Biomedical Research Institute (IDIBGI), Girona, Catalonia, Spain \\ ${ }^{3}$ Neuroimmunology and Multiple Sclerosis Unit, Dr. Josep Trueta University Hospital, Girona Biomedical Research Institute \\ (IDIBGI), Girona, Catalonia, Spain \\ ${ }^{4}$ Unit of Clinical Research, Catalan Institute of Oncology, Girona, Catalonia, Spain \\ ${ }^{5}$ Mayo Clinic, Department of Laboratory Medicine and Pathology, Division of Experimental Pathology, Rochester, MN, USA \\ ${ }^{6}$ Mayo Clinic Cancer Center, Rochester, MN, USA \\ ${ }^{7}$ Deparment of Medical Oncology, Catalan Institute of Oncology, Girona, Catalonia, Spain \\ ${ }^{8}$ Department of Medical Sciences, Medical School, University of Girona, Girona, Catalonia, Spain \\ Correspondence to: Javier A. Menendez, email: jmenendez@iconcologia.net, jmenendez@idibgi.org \\ Keywords: denosumab, RANK, RANKL, cancer stem cells, BRCA 1 \\ Received: September 26, $2016 \quad$ Accepted: February 27, $2017 \quad$ Published: March 25, 2017 \\ Copyright: Cuyàs et al. This is an open-access article distributed under the terms of the Creative Commons Attribution License \\ (CC-BY), which permits unrestricted use, distribution, and reproduction in any medium, provided the original author and source \\ are credited.
}

\section{ABSTRACT}

Denosumab, a monoclonal antibody to the receptor activator of nuclear factor-kB ligand (RANKL), might be a novel preventative therapy for BRCA1-mutation carriers at high risk of developing breast cancer. Beyond its well-recognized bone-targeted activity impeding osteoclastogenesis, denosumab has been proposed to interfere with the cross-talk between RANKL-producing sensor cells and cancer-initiating RANK+ responder cells that reside within premalignant tissues of BRCA1-mutation carriers. We herein tested the alternative but not mutually exclusive hypothesis that BRCA1 deficiency might cell-autonomously activate RANKL expression to generate cellular states with cancer stem cell (CSC)-like properties. Using isogenic pairs of normallike human breast epithelial cells in which the inactivation of a single BRCA1 allele results in genomic instability, we assessed the impact of BRCA1 haploinsufficiency on the expression status of RANK and RANKL. RANK expression remained unaltered but RANKL was dramatically up-regulated in $B R C A 1^{m u t /+}$ haploinsufficient cells relative to isogenic BRCA1 ${ }^{+/+}$parental cells. Neutralizing RANKL with denosumab significantly abrogated the ability of BRCA1 haploinsufficient cells to survive and proliferate as floating microtumors or "mammospheres" under non-adherent/non-differentiating conditions, an accepted surrogate of the relative proportion and survival of CSCs. Intriguingly, CSC-like states driven by epithelial-to-mesenchymal transition or HER2 overexpression traits responded to some extent to denosumab. We propose that breast epithelium-specific mono-allelic inactivation of BRCA1 might suffice to cellautonomously generate RANKL-addicted, denosumab-responsive CSC-like states. The convergent addiction to a hyperactive RANKL/RANK axis of CSC-like states from 


\section{genetically diverse breast cancer subtypes might inaugurate a new era of cancer prevention and treatment based on denosumab as a CSC-targeted agent.}

\section{INTRODUCTION}

Two recent studies have provided strong evidence that denosumab, a fully humanized monoclonal antibody that binds and inactivates the receptor activator of nuclear factor- $\mathrm{KB}$ ligand (RANKL), might be a novel preventative therapy for carriers of $B R C A 1 / 2$ mutations, a group of woman predisposed to high lifetime risks of breast and ovarian cancer $[1,2]$. Denosumab, by blocking osteoclast maturation, function, and survival, is currently used for the treatment of postmenopausal osteoporosis, cancer treatment-induced bone loss, and skeletal complications of malignancies [3-6]. If proven to reduce the incidence of $B R C A 1 / 2$-related carcinomas in clinical trials, the repurposing of a bone-targeted agent such as denosumab for oncology indications might inaugurate a new era of molecularly targeted pharmacological cancer prevention therapies and perhaps cancer treatments using RANKL inhibitors for millions of people worldwide [7].

The study by Penninger and colleagues demonstrated that genetic inactivation of RANKL in mammary epithelium was sufficient to significantly delay tumor onset, reduce incidence, and attenuate tumor progression in multiple models of mammary carcinogenesis [1]. Moreover, long-term subcutaneous administration of a RANKL-targeting antibody fragment (RANK-Fc) almost completely prevented the spontaneous development of pre-neoplastic lesions due to BRCA1 deficiency [1]. The findings by Lindeman and co-workers using luminal progenitor cells from histologically normal tissue obtained in the pre-neoplastic phase from carriers of BRCAI mutations revealed that highly proliferative, genomically unstable $\mathrm{RANK}^{+}$cells were the key target cancer-driven population in this high-risk group [2]. Pharmacological inhibition of RANKL in BRCA1-deficient mouse models using the RANKL inhibitor OPG-Fc or a RANKL-specific monoclonal antibody significantly delayed tumor onset, confirming the therapeutic value of targeting the RANKL/ RANK pathway to prevent breast oncogenesis in carriers of BRCA1 mutations [2]. Importantly, preliminary findings from a small cohort of patients recruited in the " $B R C A-D$ " pilot window study, which aims to evaluate the biological effects of denosumab on normal breast tissue from carriers of BRCA1 and BRCA2 mutations and high-risk, non$B R C A$ carriers [8], revealed for the first time that RANKL inhibition by denosumab significantly attenuated breast epithelial cell proliferation in carriers of BRCA1 mutations.

While the aforementioned landmark studies provide genetic and pharmacological models supporting RANKLtargeted approaches as novel preventative strategies for delaying and possibly eliminating the need for existing risk-reducing approaches in carriers of $B R C A 1 / 2$ mutations, such as tamoxifen treatment, prophylactic mastectomy and salpingo-oophorectomy $[9,10]$, the ultimate mechanisms coupling RANKL blockade with impaired initiation of breast tumorigenesis remained largely unexplored. Based on the well-known relationship between altered progesterone signaling and increased RANKL activity [11-16], it was suggested that denosumab might block mitogenic cross-talk between progesterone "sensor" cells (i.e., mature ductal cells) and the hyperactive RANK ${ }^{+}$luminal "responder" progenitors residing within premalignant tissues of carriers of BRCA1 mutations [2]. When the Penninger \& Lindeman groups reported their findings, our group was evaluating the alternative but not mutually exclusive hypothesis that RANKL/RANK signaling might operate as a molecular mechanism critical for cell-autonomous maintenance and survival of cellular states with cancer stem cell (CSC)-like properties, including self-renewal, tumor-initiation, drug resistance, and metastasis properties.

To evaluate whether BRCA1 deficiency might cellautonomously activate RANKL expression to generate RANKL-addicted CSC-like cellular states, we employed isogenic pairs of nontumorigenic, normal-like human breast epithelial cells in which a knock-in of the $185 \mathrm{del} A G$ mutation in a single BRCA1 allele results in genomic instability and accurately mimics the cell-autonomous consequences of one-hit BRCAl inactivation occurring in the breast epithelium of carriers of BRCA1 mutations [17-19]. To evaluate whether hyperactive RANKL/ RANK signaling might be essential for the generation and maintenance of CSC-like cellular states in BRCAI haploinsufficient cells, we took advantage of the functional ability of breast cancer cell lines to display a subpopulation of cells with CSC-like properties defined experimentally by their ability to to self-renew and form anchorageindependent multicellular microtumors or "mammospheres" in non-adherent, non-differentiating conditions in vitro at low frequency $[20,21]$. The mammosphere platform was employed to assess the potential of denosumab as an antiCSC agent not only in BRCAI haploinsufficient cells but also in genetically diverse breast cancer subtypes in which CSC-like states are known to be driven by molecular traits such as epithelial-to-mesenchymal transition (EMT) or HER2-oncogene overexpression (22-30). We now report the ability of denosumab to efficiently target tumorsphereinitiating, RANKL-addicted CSC-like cells in cancer-prone $B R C A 1^{\text {mut/+ }}$ breast epithelial cell populations, and also in the presence of key amplifiers of breast cancer CSC-like cellular states including EMT phenomena and HER2 activation.

\section{RESULTS}

\section{$B R C A 1$ haploinsufficiency leads to the specific up-regulation of RANKL but not RANK}

To investigate the functional importance of the RANKL/RANK signaling pathway in phenotypically 
relevant models of early tumorigenesis in $B R C A 1^{\text {mut/ } /}$ carriers, we used a well-defined experimental system of spontaneously immortal and genetically stable, non-tumorigenic MCF10A breast epithelial cells. A common BRCA1 pathogenic mutation, $185 \operatorname{del} A G$, a 2-bp deletion in the coding region close to the $\mathrm{N}$-terminus is introduced into BRCA1 by gene targeting, leading to haploinsufficiency (BRCA $1^{185 \mathrm{del} A G /+}$ ) and genomic instability [19].
To assess whether BRCA1 deficiency might suffice to cell-autonomously alter the RANKL/RANK axis in breast epithelial cells, we first assessed the impact of $B R C A 1$ haploinsufficiency on the expression status of RANK and RANKL molecules in MCF10A cells by RTPCR. As shown in Figure 1, RANKL expression was dramatically up-regulated ( $>5$-fold) in $B R C A 1^{\text {mut } /+}$ cells relative to isogenic $B R C A 1^{+/+}$parental counterparts. The expression status of RANK, however, remained unaltered in BRCA1 haploinsufficient cells (Figure 1).
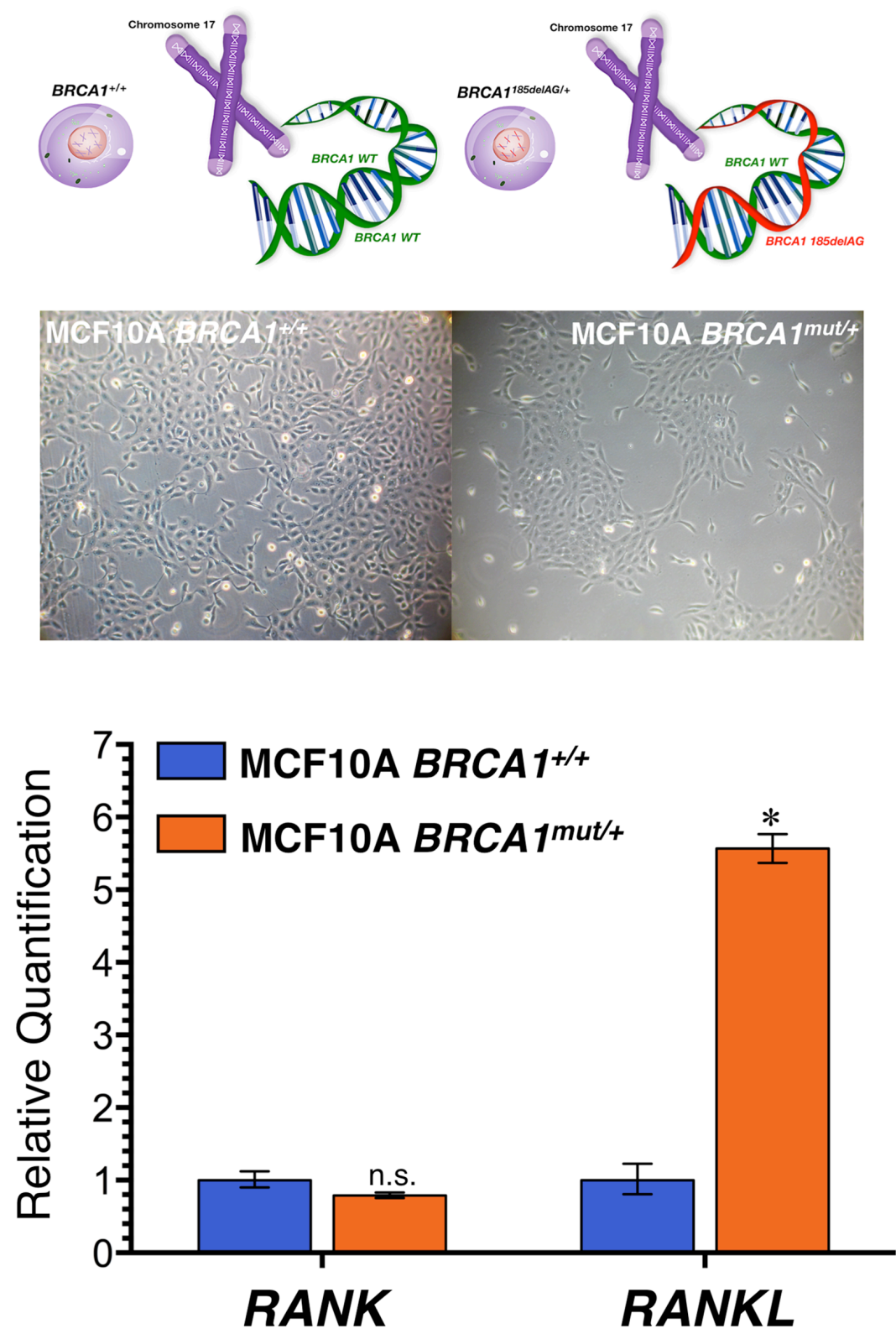

Figure 1: Mutation of a single allele of the cancer susceptibility gene $B R C A 1$ leads to activation of RANKL expression in normal-like breast epithelial cells. Top. Inactivating mutation (185delAG) of a single $B R C A 1$ allele leads to haploinsufficiency, which results in genomic instability in the spontaneously immortalized MCF10A cell line. Bottom. Total RNA from BRCA1 ${ }^{+/+}$and $B R C A 1^{m u t /+}$ MCF10A isogenic cell pairs was characterized in technical triplicates for the abundance of RANK (TNFRSF11A, Hs00921372 $\mathrm{m1}$ ) and RANKL (TNFSF11, Hs00243522_m1) relative to housekeeping genes GADPH (Hs99999905_m1) and 18S (Hs99999901_s1). The transcript abundance was calculated using the delta $\mathrm{Ct}$ method and presented as relative quantification (RQ). ${ }^{*} \mathrm{p}<0.05$. 


\section{Denosumab prevents tumorsphere formation in RANKL-overexpressing $B R C A 1^{m u t /+}$ human breast epithelial cells}

Having evidence that $B R C A 1^{m u t /+}$ cells become RANKL overexpressors, we next assessed whether a neutralizing anti-RANKL antibody such as denosumab might prevent their tumor-initiating capacity. We first tested the ability of isogenic $B R C A 1^{+/+}$and $B R C A 1^{m u t /+}$ cells to survive and proliferate as floating colonies in serum-free, anchorage-independent conditions, a widely employed in vitro assay of the self-renewal and tumorinitiating capacity of CSC-like cells $[17,18]$. Cells were treated or not with denosumab and the mammosphereforming efficiency (MSFE) was calculated as the number of sphere-like structures (diameter $>50 \mu \mathrm{m}$ ) divided by the original number of cells seeded. No differences in MSFE were observed for $B R C A 1^{+/+}$ parental cells treated or not with denosumab for 7 days (Figure 2). By contrast, MSFE was significantly lower $(70 \%)$ in $B R C A 1^{m u t++}$ cells treated with denosumab than in untreated cells. These results suggest that mammosphere-initiating CSC-like cells within $B R C A 1^{\text {mut } /+}$ cell populations are differentially more sensitive to the RANKL-targeting effects of denosumab than are those in isogenic $B R C A 1^{+/+}$cell populations.

When cell monolayers were pre-treated or not with denosumab for 3 days, trypsinized and re-plated for mammosphere assays in the absence of denosumab, no differences were observed in the mammosphereforming ability of $B R C A 1^{+/+}$parental cells. Conversely, pre-treatment with denosumab of $B R C A 1^{\text {mut } /+}$ cells notably lowered (60\%) their MSFE (Figure 2). These results show that the anti-RANKL activity of denosumab appears to preferentially target $B R C A 1^{\mathrm{mut} /+}$ cellular states with tumorsphere-initiating capacity even in the presence of a majority of non-CSC like cellular states in the setting of an attached monolayer. Denosumab-mediated suppression of mammosphereinitiating, CSC-like cells was not attributable to a general inhibition of cell proliferation and survival because cell viability measured by MTT reduction in $B R C A 1^{+/+}$and $B R C A 1^{m u t /+}$ cell monolayers was not significantly affected by exposure to denosumab (data not shown).

\section{DISCUSSION}

Based on the recent landmark studies by the Penninger \& Lindeman groups [1, 2], clinical trials are warranted to test the efficacy of the antiRANKL antibody denosumab to prevent breast/ ovarian tumorigenesis in carriers of $B R C A 1 / 2$ mutations, and likely in women with non-BRCA1/2 mutations at very high risk of developing breast/ ovarian cancer. Using a monoallelic $B R C A 1$ germline mutation model that accurately mimics the molecular events of rapid and tissue-specific predisposition of breast cancer development associated with BRCA1 haploinsufficiency, we demonstrate the ability of denosumab to robustly impair tumorsphere forming ability, a functional marker that correlates with CSC numbers in cancer cell lines and with progenitor activity in nontransformed mammary epithelial cells of $B R C A 1^{m u t /+}$ breast epithelial populations. Given the robust tumorsphere-lowering/CSC-targeting output of denosumab in cancer-prone $B R C A 1^{\text {mut/+ }}$ breast epithelial cells and the unresponsiveness to denosumab of CSC-driven tumorsphere formation in $B R C A 1^{+/+}$ isogenic cells, and considering also the absence of any confounding effect from different genetic backgrounds in the distinctive and specific anti-CSC activity of denosumab against $B R C A 1^{m u t /+}$ cell populations, these findings provide unbiased evidence to suggest that $B R C A 1$ haploinsufficiency is sufficient to generate CSClike states that functionally depend on the occurrence of hyperactive autocrine/paracrine RANKL/RANK signaling. Indeed, it is noteworthy that not all the cells within $B R C A 1^{\text {mut } /+}$ populations are necessarily addicted to the same extent to autocrine/paracrine RANKL/ RANK signaling, which appears to necessarily and exclusively operate in those cell states with tumorinitiating capacity since denosumab treatment does not affect cell viability or proliferation of $2 \mathrm{D} B R C A 1^{\mathrm{mut} /+}$ cultures but efficiently reduces the mammosphere forming capability of CSC-like cellular states, including those that might pre-exist in 2D monolayers.

The different degrees of local production of RANKL, its specific reception by RANK, and/or the potency of RANKL/RANK signaling might dictate the degree of indispensability versus dispensability of the autocrine/paracrine RANKL/RANK pathway in CSC-like versus non-CSC cellular states, respectively. In other words, the capacity of denosumab to operate as a bona fide CSC-targeting agent might depend on the convergent ability of unrelated CSC drivers (e.g., monoallelic loss of BRCA1, EMT, HER2 signaling) to activate and maintain hyperactive RANKL/RANK signaling pathway to which the CSC-like cellular states become addicted. Supporting this notion of denosumabresponsive RANKL/RANK-driven stemness, denosumab might also target de novo generation of cancer stemness via induction of the EMT program or HER2-oncogene overexpression (Box 1).

The apparent inhibitory effects of denosumab on the acquired mammosphere-forming capacity of stably induced EMT-CSCs (Box 2) might suggest that hyperactive RANKL/RANK signaling not only suffices to induce EMT-like phenomena [31-37], but also that the acquisition and maintenance of CSC-like cellular states 

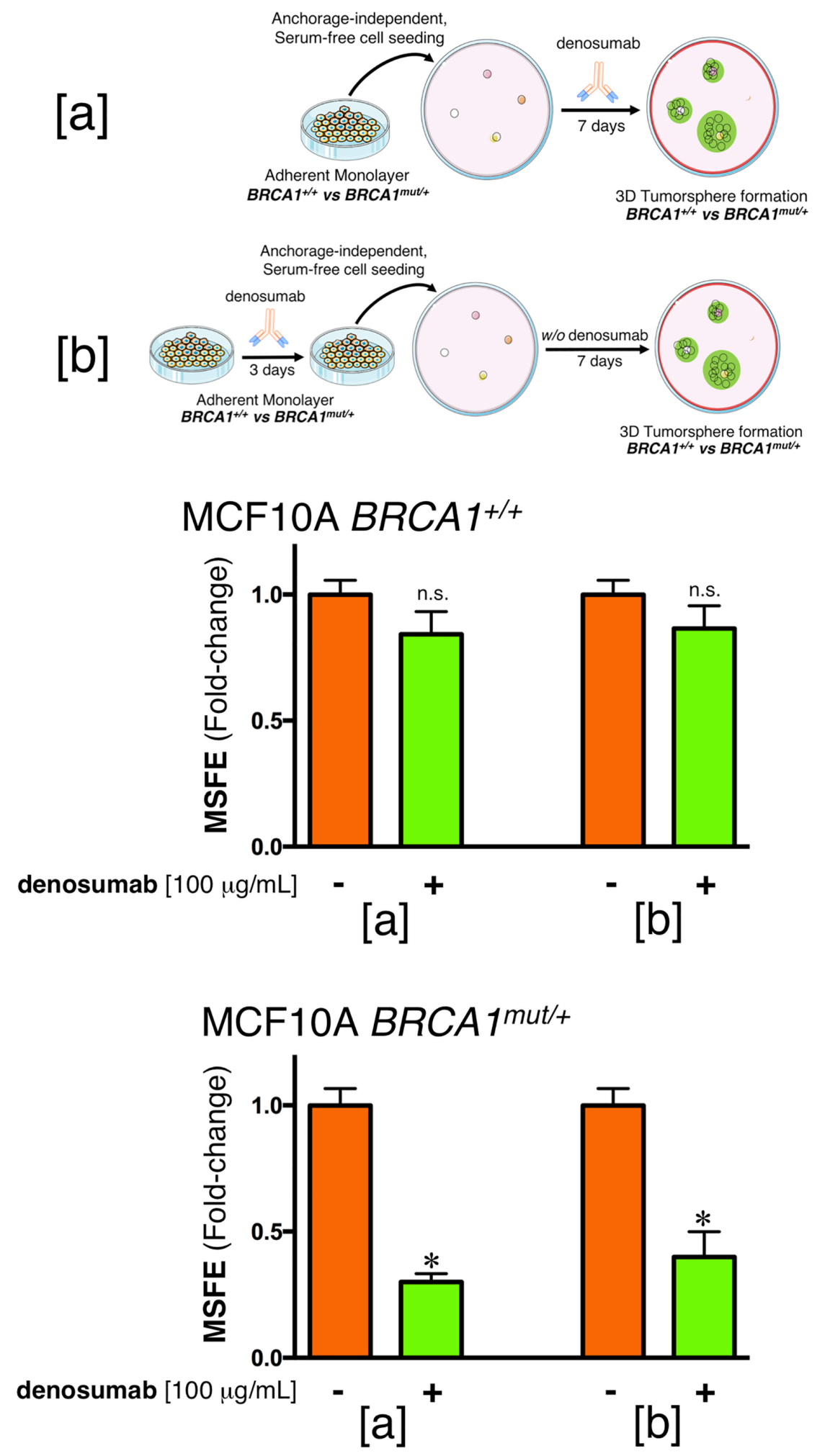

Figure 2: Denosumab significantly reduces mammosphere formation in $B R C A 1^{\text {mut/+ }}$ breast epithelial cells. (a) Mammosphere-forming efficiency (MSFE) of $B R C A 1^{+/+}$and $B R C A 1^{m u t /+} \mathrm{MCF} 10 \mathrm{~A}$ isogenic cell pairs in the absence or presence of $100 \mu \mathrm{g} /$ $\mathrm{mL}$ denosumab was calculated after 7 days and expressed as a percentage (mean \pm SD); three technical replicates per $n ; n=3$ biological replicates. The MSFE of vehicle-alone control cells was normalized to one in each isogenic model. Re-feeding of mammosphere cultures with denosumab and/or sphere medium was performed on day 4. ${ }^{*} \mathrm{p}<0.05$. (b) Monolayers of MCF10A $B R C A 1^{+/+}$and $B R C A 1^{m u t /+}$ cells were pre-treated with $100 \mu \mathrm{g} / \mathrm{mL}$ denosumab for 3 days, trypsinized and re-plated for mammosphere assays in the absence of denosumab. The MSFE of vehicle-alone control cells was normalized to one; three technical replicates per $\mathrm{n} ; \mathrm{n}=3$ biological replicates. ${ }^{*} \mathrm{p}<0.05$. 
Box1. Denosumab might target SC cellular states across multiple breast cancer subtypes. Having confirmed that $B R C A 1$ haploinsufficiency cell-autonomously activates RANKL expression and generates denosumab-responsive CSClike cellular states, we preliminary evaluated whether RANKL/RANK signaling could also favor the maintenance of CSC populations in genetically diverse subtypes of breast carcinoma cells.

Denosumab and EMT-driven CSC-like cellular states. By activating NF- $\mathrm{KB}$, the RANKL/RANK pathway has been shown to promote cell migration, invasion, and metastasis via the induction of EMT in cancer cells [31-37]. Accordingly, RANKL/RANK signaling might promote dedifferentiation processes that induce EMT and "stemness" in normal breast epithelial and breast cancer cells [38], supporting the notion that RANKL/RANK-driven tumor initiation, progression, and metastasis relies on its ability to regulate self-renewal and activity of CSC-like cells with tumor- and metastasis-initiating capacity [38-41]. To explore whether RANKL might function as a molecular link between EMT and breast cancer stemness, the RANKL-targeting activity of denosumab was studied against the background of the landmark observation that breast cancer cells experimentally induced into EMT dramatically increase the proportion of proliferative CSC-like cells, serving as a valuable screening platform for identifying agents specifically targeting CSCs $[22,23]$.

First, exploiting the observation that EMT increases the proportion of CSC-like cells ( 100-fold) within breast cancer cell populations, we employed V12H-RAS-transformed derivatives of immortalized mammary epithelial cells driven to undergo EMT by E-cadherin knockdown to assay the ability of denosumab to selectively reduce the EMTdriven enrichment of CSC-like cells [22-26]. We first confirmed previous results showing that the tumorsphere-forming ability of HMLER ${ }^{\text {shECad }}$ cells is vastly superior to that of HMLER ${ }^{\text {shCntrl }}$ cells, which mostly failed to form bona fide mammospheres (data not shown). Of note, the EMT-promoted spheroid formation capacity of HMLER cells was apparently reduced in the presence of denosumab (Figure Box 1A).

Second, to investigate whether denosumab targets CSC-like cells that have been identified within basal-like ductal carcinoma in situ (DCIS) [42-45], we used MCF10DCIS.com cells as an in vitro model representative of clinical comedo, basal-like DCIS that behaves as a precursor to invasive basal-like, triple-negative breast cancer (TNBC) [27]. It is notable that MCF10DCIS.com cells cultured as spheroids secrete vast amounts of the oncogenic protein osteopontin [46], a CD44 and integrin ligand known to up-regulate the expression of RANKL [47-49]. Although its effect was less conspicuous than in $B R C A 1^{\text {mut } /+}$ and EMT-like HMLER ${ }^{\text {shECad }}$ cell models, denosumab slightly but significantly reduced by the capacity for MCF10DCIS.com cells to form mammospheres (Figure Box 1B).

Third, to evaluate the generality of the above-mentioned findings, we assessed whether claudin-low breast subtypes displaying increased activation of the EMT program might also contain CSC-like cells responsive to denosumab. Mammosphere formation ability of MDA-MB-231 and SUM-159 cells, two highly aggressive models for claudin-low TNBC breast cancer [29,30], was apparently decreased by denosumab relative to their respective untreated controls, and this effect was particularly striking for MDA-MB-231 cells (Figure Box 1B).

Denosumab and HER2-driven CSC-like cellular states. We examined whether denosumab treatment might prevent the well-recognized ability of HER2 signaling, even in the absence of HER2 gene amplification, to expand CSClike breast cancer populations [50-57]. We previously demonstrated that HER2-negative MCF-7 luminal breast cancer cells engineered to express higher amounts of the HER2 oncoprotein (MCF-7/HER2) present a significantly increased ability over MCF-7 parental cells to form mammospheres [58]. In our hands, denosumab treatment was apparently sufficient to return the exacerbated HER2-driven tumorsphere-initiating capacity to almost baseline levels found in HER2-negative MCF-7/neo isogenic parental cells (Figure Box 1C).

might be accompanied by activation of the RANKL/ RANK signaling pathway, thus generating a positive feedback loop between the RANKL/RANK axis and EMT-related acquisition of stemness traits. Accordingly, denosumab treatment negatively influenced the number of mammospheres formed by MDA-MB-231 and SUM-159 breast cancer cell lines, two in vitro models characterized by an enrichment in EMT and CSC-like characteristics that significantly associate with disease recurrence [30, 59-61]. Denosumab-induced RANKL inhibition might not only prevent breast tumorigenesis in cancer-prone epithelial tissues but also reduce the risk of recurrence and metastasis in aggressive subtypes of breast carcinomas [39]. Indeed, the ability of denosumab to partially reduce the numerical expansion of CSC-like cells occurring in response to high signaling levels of HER2 [50] might be part of the mechanism that induces the CSC phenotype in non-CSC cells, raising the intriguing possibility of combining antiRANKL denosumab with anti-HER2 therapeutics such as trastuzumab to prevent the increase of metastasisinitiating CSCs [56, 57]. Yet, because serum denosumab concentrations have been found to range between 17.7 and $20.1 \mu \mathrm{g} / \mathrm{mL}$ at month 6 during subcutaneous 
Box2. Bone-targeted agents against breast CSCs: The case of zoledronic acid. The therapeutic potential of bone-targeted treatments with bisphosphonates (e.g., zoledronic acid) and denosumab in cancer patients might go beyond prevention of skeletal complications [68-71]. In early-stage breast carcinomas, treatment with zoledronic acid leads to improvements in disease-free and overall survival. Denosumab is associated with improved overall survival in patients with metastatic lung cancer [71, 72]. Whereas the recent studies by Penninger \& Lindeman $[5,6]$ have provided robust evidence for the direct effect of denosumab against cancer cells, it should be acknowledged that earlier preclinical data demonstrated the direct antitumor activity of zoledronic acid. However, although treatment with zoledronic acid has been found to prevent and eliminate mammosphere formation in claudin-low breast cancer cells [73], the ultimate mechanism/s underlying its ability to directly target cancer cells, including CSC-like states, appear to be multi-faceted [74-85]. Because inhibition of RANKL/ RANK-driven signaling is one of the mechanisms through which zoledronic acid exerts its effects, we tested the potential anti-CSC effect of zoledronic acid on the self-renewal capacity of EMT-driven CSC-like populations by re-evaluating the ability of HMLER ${ }^{\text {shECad }}$ cells to survive and proliferate as floating spherical colonies under non-adherent/non-differentiating conditions in the presence of graded concentrations of zoledronic acid (Figure Box2). The EMT-induced spheroid formation capability of breast epithelial cells was dose-dependently prevented (up to $98 \%$ reduction) by zoledronic acid. Importantly, full suppression of mammosphere formation was not due to non-specific toxicity of zoledronic acid because cell viability determined by MTT reduction performed in monolayer cultures remained as high as $80 \%$ in the presence of an identical concentration of zoledronic acid (i.e., $10 \mu \mathrm{mol} / \mathrm{L}$ ). Moreover, zoledronic acid dose-dependently decreased tumor sphere formation in MDA-MB-231 and SUM- 159 cells by $70 \%$ and $85 \%$, respectively (Figure Box 2 ). Once again, these decreases in mammosphereinitiating capacity of claudin-low breast cancer cells was not due to non-specific zoledronic acid toxicity because identical concentrations of zoledronic acid had no significant impact on cell viability under adherent culture conditions (data not shown).

administration of $120 \mathrm{mg}$ every 4 weeks to patients with breast cancer and bone metastasis [62], it should be acknowledged that the denosumab concentration employed in our tumorsphere assays exceeded by up to 5 -fold the circulating systemic concentrations of denosumab in patient populations.

The propensity for tumor formation in BRCA1associated breast carcinomas appears to be driven by specific molecular and cellular alterations triggered by inherited mutations in BRCA1 in breast epithelial differentiation before development of cancer. Here, we established that BRCA1 haploinsufficiency cellautonomously elicits a vicious cycle involving RANKL/RANK signaling favoring the pool of breast epithelial cells with CSC-like properties [63]. By binding to RANKL, denosumab inhibits the activation of RANK, its only receptor, thus preventing RANKL/ RANK interaction and disrupting signaling leading to expansion and maintenance of the CSC population across multiple breast cancer subtypes (Figure 3). Beyond the anticipated primary prevention impact that denosumab-targeted aberrancies in the RANKL pathway might play in BRCA1 mutation carriers [64], preliminary evidence from the ABCSG 18 trial showing improved disease-free survival of women receiving adjuvant denosumab $[65,66]$ and currently ongoing clinical investigations of denosumab as an adjunct to neoadjuvant chemotherapy [67] should begin to clarify the role of RANKL blockade to prevent CSC-driven tumor recurrence and metastasis in non-BRCA1 patients. The observations by the Penninger \& Lindeman groups $[1,2]$ together with our findings suggesting that cellautonomous activation of the RANKL/RANK signaling axis is a convergently shared, non-oncogenic addiction underlying the generation and maintenance of CSClike states in response to diverse molecular events such as BRCAl haploinsufficiency, EMT phenomena and HER2 activation, might inaugurate a new era of cancer prevention and treatment based on the previously unrecognized CSC-targeted capabilities of bone-targeted agents such as the bisphosphonate zoledronic acid (Box 2) and the anti-RANKL monoclonal antibody denosumab.

\section{Study limitations}

We should acknowledge that our mammospheres studies have used too few cell lines to reliably interpret data in the context of breast cancer-initiating cells derived from molecularly heterogeneous primary human tumors. Additional ex vivo experiments using freshly isolated CSC-enriched cell populations from specific BRCA1 KO animals and primary breast tumor samples of distinct molecular subtypes should definitely clarify the role of the anti-RANKL antibody denosumab as a potential breast CSC-specific inhibitor. 
A

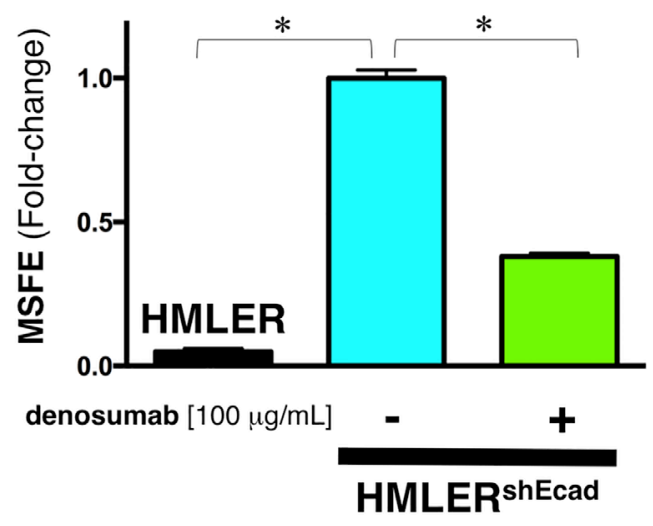

B

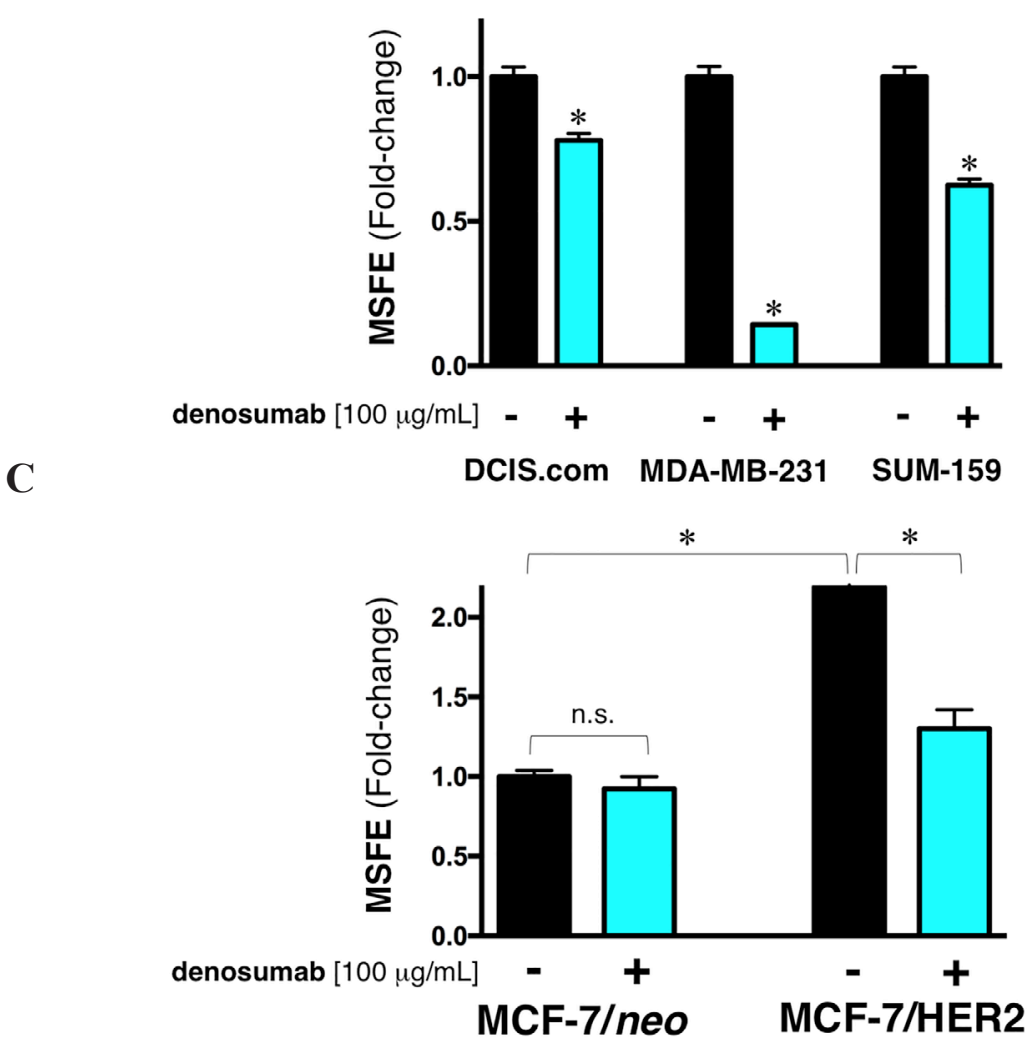

Figure Box 1: (A) Denosumab reduces the EMT-driven tumorsphere formation ability of $R A S$-transformed human breast epithelial cells. Mammosphere-forming efficiency (MSFE) of HMLER and HMLER ${ }^{\text {shEcad }}$ cells in the absence or presence of $100 \mu \mathrm{g} / \mathrm{mL}$ denosumab was calculated after 7 days and expressed as a percentage (mean $\pm \mathrm{SD}$ ); three technical replicates per $n ; n=2$ biological replicates. The MSFE of vehicle-alone HMLER ${ }^{\text {shECad }}$ control cells was normalized to one. Re-feeding of mammospheres cultures with denosumab and/or sphere medium was performed on day 4. ${ }^{*} p<0.05$. (B) Denosumab reduces mammosphere formation in basal-like and claudin-low triple negative breast cancer cells. Mammosphere-forming efficiency (MSFE) of MCF10DCIS.com (left), MDA-MB-231 (middle), and SUM-159 (right) cells in the absence or presence of $100 \mu \mathrm{g} / \mathrm{mL}$ denosumab was calculated after 7 days and expressed as a percentage (mean $\pm \mathrm{SD}$ ); three technical replicates per $\mathrm{n} ; \mathrm{n}=2$ biological replicates. The MSFE of vehicle-alone control cells was normalized to one in each model. Re-feeding of mammospheres cultures with denosumab and/or sphere medium was performed on day 4. * ${ }^{*}<0.05$. (C) Denosumab reduces HER2-driven augmentation of mammosphere-initiating CSC-like cells in luminal breast cancer cells. Mammosphere-forming efficiency (MSFE) of the HER2-negative (MCF-7/neo) and HER2-overexpressing (MCF-7/HER2) isogenic cell pair in the absence or presence of $100 \mu \mathrm{g} / \mathrm{mL}$ denosumab was calculated after 7 days and expressed as a percentage (mean $\pm S D$ ); three technical replicates per $n ; n=2$ biological replicates. The MSFE of vehicle-alone HER2-negative MCF-7 cells was normalized to one. Re-feeding of mammospheres cultures with denosumab and/or sphere medium was performed on day $4 .{ }^{*} \mathrm{p}<0.05$. 

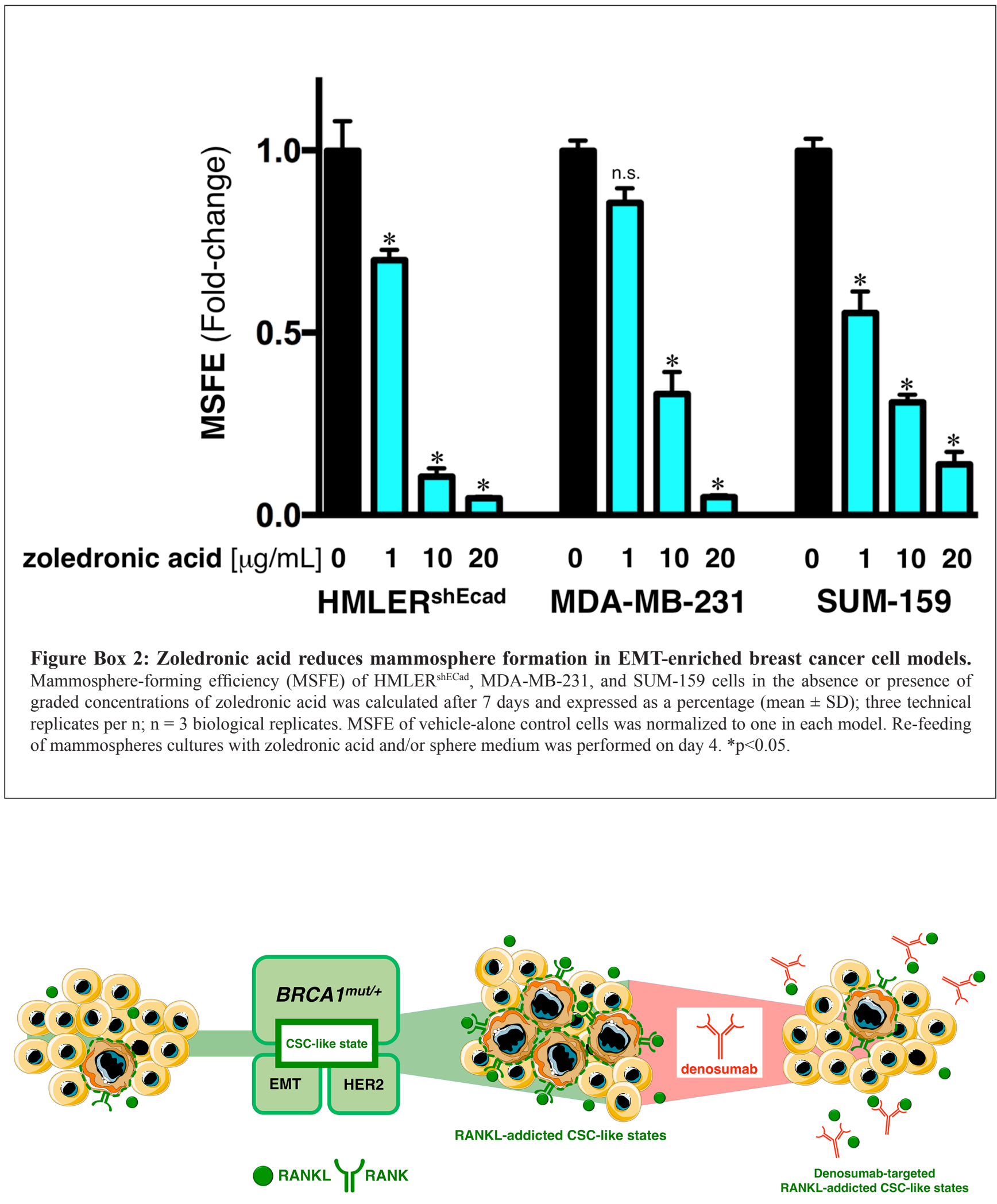

Figure 3: Autocrine/paracrine RANKL/RANK signaling: A shared denosumab-responsive CSC trait across multiple breast cancer subtypes. Tumor-initiating cell from genetically diverse pre-cancerous and breast cancer subtypes might share, to a greater (BRCA1 haploinsufficiency) or lesser extent (EMT) and HER2), a common addiction to hyperactive RANKL/RANK signaling, which allows their survival and self-renewal in a CSC state. This observation might inaugurate a new era of cancer prevention and treatment capable of producing sustained effects based on RANKL-targeting approaches. 


\section{MATERIALS AND METHODS}

\section{Materials}

Denosumab (Prolia ${ }^{\circledR}$ ) and zoledronic acid (Zometa $\left.{ }^{\circledR}\right)$ were kindly provided by the Hospital Universitari de Girona Dr. Josep Trueta Pharmacy (Girona, Spain).

\section{Cell lines}

Human BRCA1 (185delAG/+) MCF10A cells with a heterozygous knock-in of a 2-bp deletion of BRCA1 resulting in a premature termination codon at position 39 and MCF10A isogenic parental cells were obtained from Horizon Discovery Ltd., Cambridge, UK (Cat\# HD 101018 and HD PAR-058, respectively). Cells were routinely grown in DMEM/F-12 (Gibco, Life Technologies, Paisley, UK) including $2.5 \mathrm{mmol} / \mathrm{L} \mathrm{L}$-glutamine, and $15 \mathrm{mmol} / \mathrm{L}$ HEPES, supplemented with 5\% $(v / v)$ horse serum (HS), 10 $\mu \mathrm{g} / \mathrm{mL}$ insulin, $20 \mathrm{ng} / \mathrm{mL}$ hEGF, $0.5 \mu \mathrm{g} / \mathrm{mL}$ hydrocortisone and $0.1 \mu \mathrm{g} / \mathrm{mL}$ cholera toxin.

HMLER cells expressing a control shRNA (shCntrl) or an shRNA targeting E-cadherin (shEcad) were generated as described $[22,23]$ and maintained in a 1:1 mixture of DMEM $+10 \%(v / v)$ heat-inactivated fetal bovine serum (FBS), insulin, hydrocortisone, and Clonetics $^{\mathrm{TM}}$ MEGM $^{\mathrm{TM}}$ (Mammary Epithelial Cell Growth Medium).

MCF10DCIS.com and SUM-159PT cells were purchased from Asterand (Detroit, MI). DCIS.com cells were cultured in DMEM/F12 with L-glutamine supplemented with 5\% HS and penicillin/streptomycin. SUM159PT cells were cultured in Ham's F12 with 5\% FBS, $5 \mu \mathrm{g} / \mathrm{mL}$ insulin, and $1 \mu \mathrm{g} / \mathrm{mL}$ hydrocortisone.

MDA-MB-231 cells were purchased from American Type Culture Collection (Manassas, VA) and grown in Improved MEM supplemented with 5\% FBS and 2 $\mathrm{mmol} / \mathrm{L}$ L-glutamine.

HER2-overexpressing MCF-7/HER2 (clone 18) cells and their matched isogenic control (empty vectortransfected) MCF-7/neo cells were kindly provided by Mien-Chie Hung (The University of Texas MD Anderson Cancer Center, Houston, TX). Breast cancer cell lines were routinely grown in improved MEM (IMEM; Biosource International, Camarillo, CA, USA) containing 5\% (v/v) FBS and $2 \mathrm{mmol} / \mathrm{L}$ L-glutamine.

All cells were maintained at $37^{\circ} \mathrm{C}$ in a humidified atmosphere of $95 \%$ air $/ 5 \% \mathrm{CO}_{2}$. Cells were screened periodically for Mycoplasma contamination.

\section{Quantitative real-time polymerase chain reaction (qRT-PCR)}

Total RNA was extracted from cell cultures using the Qiagen RNeasy Kit and QIAshredder columns according to the manufacturer's instructions. One microgram of total RNA was reverse-transcribed to cDNA using the Reaction Ready ${ }^{\mathrm{TM}}$ First Strand cDNA Synthesis Kit (SABiosciences, Frederick, MD). PCR arrays were processed according to the SABiosciences RT-PCR manual and analyzed using an Applied Biosystems 7500 Fast Real-Time PCR System with an automated baseline and threshold cycle detection. The data were interpreted using the web-based PCR array analysis tool from SABiosciences.

\section{Mammosphere culture and mammosphere- forming efficiency}

Single cell suspensions of cell lines were plated in 6-well tissue culture plates previously coated with poly-2-hydroxyethyl-methacrylate (Sigma, St. Louis, MO) to prevent cell attachment, at a density of 1000 cells/mL in serum-free DMEM/F-12 supplemented with $1 \%$ L-glutamine, $1 \%$ penicillin/streptomycin, 2\% B27 (Invitrogen, Carlsbad, CA), $20 \mathrm{ng} / \mathrm{mL}$ EGF (Sigma) and $20 \mathrm{ng} / \mathrm{mL} \mathrm{FGFb}$ (Invitrogen). The medium was made semi-solid by the addition of $0.5 \%$ methylcellulose (R\&D Systems, Minneapolis, MN) to prevent cell aggregation. Mammosphere-forming efficiency (MSFE) was calculated as the number of sphere-like structures (diameter $>50$ $\mu \mathrm{m})$ formed after 7 days in the absence or presence of denosumab or zoledronic acid, divided by the original number of cells seeded and expressed as a percentage (mean $\pm \mathrm{SD}$ ).

\section{Cell viability assays}

Cell viability was determined using the standard colorimetric MTT reduction assay. For each treatment, cell viability was evaluated as a percentage using the following equation: $\left(\mathrm{OD}_{570}\right.$ of the treated sample/ $\mathrm{OD}_{570}$ of the untreated sample $) \times 100$.

\section{Statistical analysis}

All observations were confirmed by at least three independent experiments. Data are presented as mean \pm SD. Two-group comparisons were performed using Student's $t$ test for paired and unpaired values. Comparisons of means of $\geq 3$ groups were performed by ANOVA, and the existence of individual differences, in case of significant $F$ values at ANOVA, tested by Scheffe's multiple contrasts. $P$ values $<0.05$ were considered statistically significant (denoted as*). All statistical tests were two-sided.

\section{ACKNOWLEDGMENTS}

We are greatly indebted to Prof. Robert A. Weinberg (Whitehead Institute for Biomedical Research, Cambridge, MA) for providing the HMLER ${ }^{\text {shCntrol }}$ and HMLER ${ }^{\text {shEcad }}$ cells used in this work. This work was supported by grants from the Ministerio de 
Ciencia e Innovación (Grant SAF2016-80639-P to J. A. Menendez), Plan Nacional de I+D +I, Spain and the Agència de Gestió d'Ajuts Universitaris i de Recerca (AGAUR) (Grant 2014 SGR229 to J. A. Menendez), Departament d'Economia i Coneixement, Catalonia, Spain. Elisabet Cuyàs is supported by the Sara Borrell post-doctoral contract (CD15/00033) from the Ministerio de Sanidad y Consumo, Fondo de Investigación Sanitaria (FIS), Spain. María Muñoz-San Martín is supported by the 2016 FI B01171 AGAUR fellowship. Joaquim Bosch-Barrera was supported by an Emerging Research Grant (2013) from the Spanish Society of Medical Oncology (SEOM, Madrid, Spain), and a Research Grant from Pfizer (WI190764). The authors would like to thank Dr. Kenneth McCreath for editorial support.

\section{CONFLICTS OF INTEREST}

The authors declare no conflicts of interest.

\section{REFERENCES}

1. Sigl V, Owusu-Boaitey K, Joshi PA, Kavirayani A, Wirnsberger G, Novatchkova M, Kozieradzki I, Schramek D, Edokobi N, Hersl J, Sampson A, Odai-Afotey A, Lazaro C, et al. RANKL/RANK control Brcal mutation-driven mammary tumors. Cell Res. 2016;26:761-74.

2. Nolan E, Vaillant F, Branstetter D, Pal B, Giner G, Whitehead L, Lok SW, Mann GB, Kathleen Cuningham Foundation Consortium for Research into Familial Breast Cancer (kConFab), Rohrbach K, Huang LY, Soriano R, Smyth GK, et al. RANK ligand as a potential target for breast cancer prevention in BRCA1-mutation carriers. Nat Med. 2016;22:933-9.

3. Lacey DL, Boyle WJ, Simonet WS, Kostenuik PJ, Dougall WC, Sullivan JK, San Martin J, Dansey R. Bench to bedside: elucidation of the OPG-RANK-RANKL pathway and the development of denosumab. Nat Rev Drug Discov. 2012;11:401-19.

4. Lewiecki EM, Bilezikian JP. Denosumab for the treatment of osteoporosis and cancer-related conditions. Clin Pharmacol Ther. 2012;91:123-33.

5. Casas A, Llombart A, Martín M. Denosumab for the treatment of bone metastases in advanced breast cancer. Breast. 2013;22:585-92.

6. Rolfo C, Raez LE, Russo A, Reguart N, Campelo RG, Bronte G, Papadimitriou K, Silvestris F. Molecular target therapy for bone metastasis: starting a new era with denosumab, a RANKL inhibitor. Expert Opin Biol Ther. 2014;14:15-26.

7. Galluzzi L, Buqué A, Kroemer G. Prevention of breast cancer by RANKL/RANK blockade. Cell Res. 2016;26:751-2.
8. https://www.anzctr.org.au/Trial/Registration/TrialReview. aspx?ACTRN=12614000694617

9. Roukos DH, Briasoulis E. Individualized preventive and therapeutic management of hereditary breast ovarian cancer syndrome. Nat Clin Pract Oncol. 2007;4:578-90.

10. Harmsen MG, Hermens RP, Prins JB, Hoogerbrugge N, de Hullu JA. How medical choices influence quality of life of women carrying a BRCA mutation. Crit Rev Oncol Hematol. 2015;96:555-68.

11. Gonzalez-Suarez E, Jacob AP, Jones J, Miller R, RoudierMeyer MP, Erwert R, Pinkas J, Branstetter D, Dougall WC. RANK ligand mediates progestin-induced mammary epithelial proliferation and carcinogenesis. Nature. 2010;468:103-7.

12. González-Suárez E, Sanz-Moreno A. RANK as a therapeutic target in cancer. FEBS J. 2016;283:2018-33.

13. Widschwendter M, Burnell M, Fraser L, Rosenthal AN, Philpott S, Reisel D, Dubeau L, Cline M, Pan Y, Yi PC, Gareth Evans D, Jacobs IJ, Menon U, et al. Osteoprotegerin (OPG), The Endogenous Inhibitor of Receptor Activator of NF- $\kappa$ B Ligand (RANKL), is Dysregulated in BRCA Mutation Carriers. EBioMedicine. 2015;2:1331-9.

14. Hu H, Wang J, Gupta A, Shidfar A, Branstetter D, Lee O, Ivancic D, Sullivan M, Chatterton RT Jr, Dougall WC, Khan SA. RANKL expression in normal and malignant breast tissue responds to progesterone and is up-regulated during the luteal phase. Breast Cancer Res Treat. 2014;146:515-23.

15. Tanos T, Sflomos G, Echeverria PC, Ayyanan A, Gutierrez M, Delaloye JF, Raffoul W, Fiche M, Dougall W, Schneider $\mathrm{P}$, Yalcin-Ozuysal O, Brisken C. Progesterone/RANKL is a major regulatory axis in the human breast. Sci Transl Med. 2013;5:182ra55.

16. Schramek D, Leibbrandt A, Sigl V, Kenner L, Pospisilik JA, Lee HJ, Hanada R, Joshi PA, Aliprantis A, Glimcher L, Pasparakis M, Khokha R, Ormandy CJ, et al. Osteoclast differentiation factor RANKL controls development of progestin-driven mammary cancer. Nature. 2010;468:98-102.

17. Konishi H, Mohseni M, Tamaki A, Garay JP, Croessmann S, Karnan S, Ota A, Wong HY, Konishi Y, Karakas B, Tahir K, Abukhdeir AM, Gustin JP, et al. Mutation of a single allele of the cancer susceptibility gene BRCA1 leads to genomic instability in human breast epithelial cells. Proc Natl Acad Sci U S A. 2011;108:17773-8.

18. Menendez JA, Folguera-Blasco N, Cuyàs E, FernándezArroyo S, Joven J, Alarcón T. Accelerated geroncogenesis in hereditary breast-ovarian cancer syndrome. Oncotarget. 2016;7:11959-71. doi: 10.18632/oncotarget.7867.

19. Cuyàs E, Fernández-Arroyo $\mathrm{S}$, Alarcón T, Lupu R, Joven $\mathrm{J}$, Menendez JA. Germline BRCA1 mutation reprograms breast epithelial cell metabolism towards mitochondrialdependent biosynthesis: Evidence for metformin-based "starvation" strategies in BRCA1 carriers. Oncotarget. 2016; 7:52974-52992. doi: 10.18632/oncotarget.9732. 
20. Manuel Iglesias J, Beloqui I, Garcia-Garcia F, Leis O, Vazquez-Martin A, Eguiara A, Cufi S, Pavon A, Menendez JA, Dopazo J, Martin AG. Mammosphere formation in breast carcinoma cell lines depends upon expression of E-cadherin. PLoS One. 2013;8:e77281.

21. Lee $\mathrm{CH}, \mathrm{Yu} \mathrm{CC}$, Wang BY, Chang WW. Tumorsphere as an effective in vitro platform for screening anti-cancer stem cell drugs. Oncotarget. 2016;7:1215-26. doi: 10.18632/ oncotarget.6261.

22. Mani SA, Guo W, Liao MJ, Eaton EN, Ayyanan A, Zhou AY, Brooks M, Reinhard F, Zhang CC, Shipitsin M, Campbell LL, Polyak K, Brisken C, et al. The epithelialmesenchymal transition generates cells with properties of stem cells. Cell. 2008; 133:704-715.

23. Gupta PB, Onder TT, Jiang G, Tao K, Kuperwasser C, Weinberg RA, Lander ES. Identification of selective inhibitors of cancer stem cells by high-throughput screening. Cell. 2009; 138:645-659.

24. Cuyàs E, Corominas-Faja $\mathrm{B}$, Menendez JA. The nutritional phenome of EMT-induced cancer stem-like cells. Oncotarget. 2014;5:3970-82. doi: 10.18632/oncotarget.2147.

25. Bhowmik SK, Ramirez-Peña E, Arnold JM, Putluri V, Sphyris N, Michailidis G, Putluri N, Ambs S, Sreekumar A, Mani SA. EMT-induced metabolite signature identifies poor clinical outcome. Oncotarget. 2015;6:42651-60. doi: 10.18632/oncotarget.4765.

26. Gonzalez-Guerrico AM, Espinoza I, Schroeder B, Park $\mathrm{CH}$, Kvp CM, Khurana A, Corominas-Faja B, Cuyàs E, Alarcón T, Kleer C, Menendez JA, Lupu R. Suppression of endogenous lipogenesis induces reversion of the malignant phenotype and normalized differentiation in breast cancer. Oncotarget. 2016; 7:71151-71168. doi: 10.18632/ oncotarget.9463.

27. Behbod F, Kittrell FS, LaMarca H, Edwards D, Kerbawy S, Heestand JC, Young E, Mukhopadhyay P, Yeh HW, Allred DC, Hu M, Polyak K, Rosen JM, et al. An intraductal human-in-mouse transplantation model mimics the subtypes of ductal carcinoma in situ. Breast Cancer Res. 2009;11:R66.

28. Barnabas N, Cohen D. Phenotypic and Molecular Characterization of MCF10DCIS and SUM Breast Cancer Cell Lines. Int J Breast Cancer. 2013;2013:872743.

29. Prat A, Parker JS, Karginova O, Fan C, Livasy C, Herschkowitz JI, He X, Perou CM. Phenotypic and molecular characterization of the claudin-low intrinsic subtype of breast cancer. Breast Cancer Res. 2010;12:R68.

30. Sarkar TR, Battula VL, Werden SJ, Vijay GV, Ramirez-Peña EQ, Taube JH, Chang JT, Miura N, Porter W, Sphyris N, Andreeff M, Mani SA. GD3 synthase regulates epithelialmesenchymal transition and metastasis in breast cancer. Oncogene. 2015;34:2958-67.

31. Odero-Marah VA, Wang R, Chu G, Zayzafoon M, Xu J, Shi C, Marshall FF, Zhau HE, Chung LW. Receptor activator of NF-kappaB Ligand (RANKL) expression is associated with epithelial to mesenchymal transition in human prostate cancer cells. Cell Res. 2008;18:858-70.

32. Yamada T, Tsuda M, Takahashi T, Totsuka Y, Shindoh M, Ohba Y. RANKL expression specifically observed in vivo promotes epithelial mesenchymal transition and tumor progression. Am J Pathol. 2011;178:2845-56.

33. Tsubaki $\mathrm{M}$, Komai $\mathrm{M}$, Fujimoto $\mathrm{S}$, Itoh $\mathrm{T}$, Imano $\mathrm{M}$, Sakamoto K, Shimaoka H, Takeda T, Ogawa N, Mashimo K, Fujiwara D, Mukai J, Sakaguchi K, et al. Activation of NF- $\kappa \mathrm{B}$ by the RANKL/RANK system up-regulates snail and twist expressions and induces epithelial-tomesenchymal transition in mammary tumor cell lines. J Exp Clin Cancer Res. 2013;32:62.

34. Song FN, Duan M, Liu LZ, Wang ZC, Shi JY, Yang LX, Zhou J, Fan J, Gao Q, Wang XY. RANKL promotes migration and invasion of hepatocellular carcinoma cells via NF- $\kappa \mathrm{B}-$ mediated epithelial-mesenchymal transition. PLoS One. 2014;9:e108507.

35. Liu Y, Wang J, Ni T, Wang L, Wang Y, Sun X. CCL20 mediates RANK/RANKL-induced epithelial-mesenchymal transition in endometrial cancer cells. Oncotarget. 2016;7:25328-39. doi: 10.18632/oncotarget.8291.

36. Chakrabarti R, Wei Y, Romano RA, DeCoste C, Kang Y, Sinha S. Elf5 regulates mammary gland stem/progenitor cell fate by influencing notch signaling. Stem Cells. 2012;30:1496-508.

37. Chakrabarti R, Hwang J, Andres Blanco M, Wei Y, Lukačišin M, Romano RA, Smalley K, Liu S, Yang Q, Ibrahim T, Mercatali L, Amadori D, Haffty BG, et al. Elf5 inhibits the epithelial-mesenchymal transition in mammary gland development and breast cancer metastasis by transcriptionally repressing Snail2. Nat Cell Biol. 2012;14:1212-22.

38. Pellegrini P, Cordero A, Gallego MI, Dougall WC, Muñoz P, Pujana MA, Gonzalez-Suarez E. Constitutive activation of RANK disrupts mammary cell fate leading to tumorigenesis. Stem Cells. 2013;31:1954-65.

39. Palafox M, Ferrer I, Pellegrini P, Vila S, HernandezOrtega S, Urruticoechea A, Climent F, Soler MT, Muñoz P, Viñals F, Tometsko M, Branstetter D, Dougall WC, et al. RANK induces epithelial-mesenchymal transition and stemness in human mammary epithelial cells and promotes tumorigenesis and metastasis. Cancer Res. 2012;72:2879-88

40. Cordero A, Pellegrini P, Sanz-Moreno A, Trinidad EM, Serra-Musach J, Deshpande C, Dougall WC, Pujana MA, González-Suárez E. Rankl Impairs Lactogenic Differentiation Through Inhibition of the Prolactin/Stat5 Pathway at Midgestation. Stem Cells. 2016;34:1027-39.

41. Yoldi G, Pellegrini P, Trinidad EM, Cordero A, GomezMiragaya J, Serra-Musach J, Dougall WC, Munoz P, Pujana MA, Planelles L, Gonzalez-Suarez E. RANK signaling blockade reduces breast cancer recurrence by inducing tumor cell differentiation. Cancer Res. 2016; 76:5857-69. 
42. Pandey PR, Xing F, Sharma S, Watabe M, Pai SK, IiizumiGairani M, Fukuda K, Hirota S, Mo YY, Watabe K. Elevated lipogenesis in epithelial stem-like cell confers survival advantage in ductal carcinoma in situ of breast cancer. Oncogene. 2013;32:5111-22.

43. Li Q, Yao Y, Eades G, Liu Z, Zhang Y, Zhou Q. Downregulation of miR-140 promotes cancer stem cell formation in basal-like early stage breast cancer. Oncogene. 2014;33:2589-600.

44. Li Q, Eades G, Yao Y, Zhang Y, Zhou Q. Characterization of a stem-like subpopulation in basal-like ductal carcinoma in situ (DCIS) lesions. J Biol Chem. 2014;289:1303-12.

45. Duru N, Gernapudi R, Lo PK, Yao Y, Wolfson B, Zhang Y, Zhou Q. Characterization of the CD49f+/CD44+/CD24single-cell derived stem cell population in basal-like DCIS cells. Oncotarget. 2016; 7:47511-47525. doi: 10.18632/ oncotarget. 10203.

46. Shevde LA, Metge BJ, Mitra A, Xi Y, Ju J, King JA, Samant RS. Spheroid-forming subpopulation of breast cancer cells demonstrates vasculogenic mimicry via hsa-miR-299-5p regulated de novo expression of osteopontin. J Cell Mol Med. 2010;14:1693-706.

47. Ishii $\mathrm{T}$, Ohshima $\mathrm{S}$, Ishida $\mathrm{T}$, Mima $\mathrm{T}$, Tabunoki $\mathrm{Y}$, Kobayashi H, Maeda M, Uede T, Liaw L, Kinoshita N, Kawase I, Saeki Y. Osteopontin as a positive regulator in the osteoclastogenesis of arthritis. Biochem Biophys Res Commun. 2004;316:809-15.

48. Desai B, Rogers MJ, Chellaiah MA. Mechanisms of osteopontin and CD44 as metastatic principles in prostate cancer cells. Mol Cancer. 2007;6:18.

49. Nakamura H, Hiraga T, Ninomiya T, Hosoya A, Fujisaki $\mathrm{N}$, Yoneda $\mathrm{T}$, Ozawa $\mathrm{H}$. Involvement of cell-cell and cell-matrix interactions in bone destruction induced by metastatic MDA-MB-231 human breast cancer cells in nude mice. J Bone Miner Metab. 2008;26:642-7.

50. Korkaya H, Paulson A, Iovino F, Wicha MS. HER2 regulates the mammary stem/progenitor cell population driving tumorigenesis and invasion. Oncogene. 2008;27:6120-30.

51. Li X, Lewis MT, Huang J, Gutierrez C, Osborne CK, Wu MF, Hilsenbeck SG, Pavlick A, Zhang X, Chamness GC, Wong H, Rosen J, Chang JC. Intrinsic resistance of tumorigenic breast cancer cells to chemotherapy. J Natl Cancer Inst. 2008;100:672-9.

52. Magnifico A, Albano L, Campaner S, Delia D, Castiglioni F, Gasparini P, Sozzi G, Fontanella E, Menard S, Tagliabue E. Tumor-initiating cells of HER2-positive carcinoma cell lines express the highest oncoprotein levels and are sensitive to trastuzumab. Clin Cancer Res. 2009;15:2010-21.

53. Roesler R, Cornelio DB, Abujamra AL, Schwartsmann G. HER2 as a cancer stem-cell target. Lancet Oncol. 2010;11:225-6.

54. Nakanishi T, Chumsri S, Khakpour N, Brodie AH, Leyland-Jones B, Hamburger AW, Ross DD, Burger AM.
Side-population cells in luminal-type breast cancer have tumour-initiating cell properties, and are regulated by HER2 expression and signalling. Br J Cancer. 2010;102:815-26.

55. Martin-Castillo B, Lopez-Bonet E, Cuyàs E, Viñas G, Pernas S, Dorca J, Menendez JA. Cancer stem cell-driven efficacy of trastuzumab (Herceptin): towards a reclassification of clinically HER2-positive breast carcinomas. Oncotarget. 2015;6:32317-38. doi: 10.18632/oncotarget.6094.

56. Ithimakin S, Day KC, Malik F, Zen Q, Dawsey SJ, BersanoBegey TF, Quraishi AA, Ignatoski KW, Daignault S, Davis A, Hall CL, Palanisamy N, Heath AN, et al. HER2 drives luminal breast cancer stem cells in the absence of HER2 amplification: implications for efficacy of adjuvant trastuzumab. Cancer Res. 2013;73:1635-46.

57. Korkaya H, Wicha MS. HER2 and breast cancer stem cells: more than meets the eye. Cancer Res. 2013;73:3489-93.

58. Corominas-Faja B, Cuyàs E, Gumuzio J, Bosch-Barrera J, Leis O, Martin ÁG, Menendez JA. Chemical inhibition of acetyl-CoA carboxylase suppresses self-renewal growth of cancer stem cells. Oncotarget. 2014;5:8306-16. doi: 10.18632/oncotarget.2059.

59. May CD, Sphyris N, Evans KW, Werden SJ, Guo W, Mani SA. Epithelial-mesenchymal transition and cancer stem cells: a dangerously dynamic duo in breast cancer progression. Breast Cancer Res. 2011;13:202.

60. Morel AP, Hinkal GW, Thomas C, Fauvet F, Courtois-Cox $\mathrm{S}$, Wierinckx A, Devouassoux-Shisheboran M, Treilleux I, Tissier A, Gras B, Pourchet J, Puisieux I, Browne GJ, et al. EMT inducers catalyze malignant transformation of mammary epithelial cells and drive tumorigenesis towards claudin-low tumors in transgenic mice. PLoS Genet. 2012;8:e1002723.

61. Cuyàs E, Martin-Castillo B, Corominas-Faja B, Massaguer A, Bosch-Barrera J, Menendez JA. Anti-protozoal and antibacterial antibiotics that inhibit protein synthesis kill cancer subtypes enriched for stem cell-like properties. Cell Cycle. 2015;14:3527-32.

62. Sohn W, Simiens MA, Jaeger K, Hutton S, Jang G. The pharmacokinetics and pharmacodynamics of denosumab in patients with advanced solid tumours and bone metastases: a systematic review. Br J Clin Pharmacol. 2014;78:477-87.

63. Sharma B, Singh RK. Emerging candidates in breast cancer stem cell maintenance, therapy resistance and relapse. J Carcinog. 2011;10:36.

64. Kotsopoulos J, Singer C, Narod SA. Can we prevent BRCA1-associated breast cancer by RANKL inhibition? Breast Cancer Res Treat. 2016; 161:11-16.

65. Gnant M, Pfeiler G, Dubsky PC, Hubalek M, Greil R, Jakesz R, Wette V, Balic M, Haslbauer F, Melbinger E, Bjelic-Radisic V, Artner-Matuschek S, Fitzal F, et al. Adjuvant denosumab in breast cancer (ABCSG-18): a multicentre, randomised, double-blind, placebo-controlled trial. Lancet. 2015;386:433-43. 
66. Gnant M, G Pfeiler, Dubsky PC, Hubalek M, Greil R, Jakesz R, Wette V, Balic M, Haslbauer F, MelbingerZeinitzer E, Bjelic-Radisic V, Artner-Matuschek S, Fitzal F, et al. The impact of adjuvant denosumab on disease-free survival: Results from 3,425 postmenopausal patients of the ABCSG-18 trial. Cancer Res. 76:S2-02.

67. https://clinicaltrials.gov/ct2/show/NCT02682693

68. Coleman R, Gnant M, Morgan G, Clezardin P. Effects of bone-targeted agents on cancer progression and mortality. $\mathrm{J}$ Natl Cancer Inst. 2012;104:1059-67.

69. Gnant M, Clézardin P. Direct and indirect anticancer activity of bisphosphonates: a brief review of published literature. Cancer Treat Rev. 2012;38:407-15.

70. Bosch-Barrera J, Merajver SD, Menéndez JA, Van Poznak C. Direct antitumour activity of zoledronic acid: preclinical and clinical data. Clin Transl Oncol. 2011;13:148-55.

71. De Castro J, García R, Garrido P, Isla D, Massuti B, Blanca B, Vázquez J. Therapeutic Potential of Denosumab in Patients With Lung Cancer: Beyond Prevention of Skeletal Complications. Clin Lung Cancer. 2015;16:431-46.

72. Scagliotti GV, Hirsh V, Siena S, Henry DH, Woll PJ, Manegold C, Solal-Celigny P, Rodriguez G, Krzakowski M, Mehta ND, Lipton L, García-Sáenz JA, Pereira JR, et al. Overall survival improvement in patients with lung cancer and bone metastases treated with denosumab versus zoledronic acid: subgroup analysis from a randomized phase 3 study. J Thorac Oncol. 2012;7:1823-9.

73. Schech AJ, Kazi AA, Gilani RA, Brodie AH. Zoledronic acid reverses the epithelial-mesenchymal transition and inhibits self-renewal of breast cancer cells through inactivation of NF- $\mathrm{KB}$. Mol Cancer Ther. 2013;12:1356-66.

74. Blake ML, Tometsko M, Miller R, Jones JC, Dougall WC. RANK expression on breast cancer cells promotes skeletal metastasis. Clin Exp Metastasis. 2014;31:233-45.

75. Jia XH, Du Y, Mao D, Wang ZL, He ZQ, Qiu JD, Ma XB, Shang WT, Ding D, Tian J. Zoledronic acid prevents the tumor-promoting effects of mesenchymal stem cells via MCP-1 dependent recruitment of macrophages. Oncotarget. 2015;6:26018-28. doi: 10.18632/oncotarget.4658.

76. Bizzarro V, Belvedere R, Milone MR, Pucci B, Lombardi R, Bruzzese F, Popolo A, Parente L, Budillon A, Petrella A. Annexin A1 is involved in the acquisition and maintenance of a stem cell-like/aggressive phenotype in prostate cancer cells with acquired resistance to zoledronic acid. Oncotarget. 2015;6:25076-92. doi: 10.18632/oncotarget.4725.
77. Marra M, Santini D, Meo G, Vincenzi B, Zappavigna S, Baldi A, Rosolowski M, Tonini G, Loeffler M, Lupu R, Addeo SR, Abbruzzese A, Budillon A, et al. Cyr61 downmodulation potentiates the anticancer effects of zoledronic acid in androgen-independent prostate cancer cells. Int J Cancer. 2009;125:2004-13.

78. Espinoza I, Liu H, Busby R, Lupu R. CCN1, a candidate target for zoledronic acid treatment in breast cancer. Mol Cancer Ther. 2011;10:732-41.

79. Kato J, Futamura M, Kanematsu M, Gaowa S, Mori R, Tanahashi T, Matsuhashi N, Yoshida K. Combination therapy with zoledronic acid and cetuximab effectively suppresses growth of colorectal cancer cells regardless of KRAS status. Int J Cancer. 2016;138:1516-27.

80. Stachnik A, Yuen T, Iqbal J, Sgobba M, Gupta Y, Lu P, Colaianni G, Ji Y, Zhu LL, Kim SM, Li J, Liu P, Izadmehr $\mathrm{S}$, et al. Repurposing of bisphosphonates for the prevention and therapy of nonsmall cell lung and breast cancer. Proc Natl Acad Sci U S A. 2014;111:17995-8000.

81. Yuen T, Stachnik A, Iqbal J, Sgobba M, Gupta Y, Lu P, Colaianni G, Ji Y, Zhu LL, Kim SM, Li J, Liu P, Izadmehr $\mathrm{S}$, et al. Bisphosphonates inactivate human EGFRs to exert antitumor actions. Proc Natl Acad Sci U S A. 2014;111:17989-94.

82. Pan B, Farrugia AN, To LB, Findlay DM, Green J, Lynch K, Zannettino AC. The nitrogen-containing bisphosphonate, zoledronic acid, influences RANKL expression in human osteoblast-like cells by activating TNF-alpha converting enzyme (TACE). J Bone Miner Res. 2004;19:147-54.

83. Kimachi K, Kajiya H, Nakayama S, Ikebe T, Okabe K. Zoledronic acid inhibits RANK expression and migration of osteoclast precursors during osteoclastogenesis. Naunyn Schmiedebergs Arch Pharmacol. 2011;383:297-308.

84. Tai TW, Su FC, Chen CY, Jou IM, Lin CF. Activation of p38 MAPK-regulated Bcl-xL signaling increases survival against zoledronic acid-induced apoptosis in osteoclast precursors. Bone. 2014;67:166-74.

85. Nakagawa T, Ohta K, Kubozono K, Ishida Y, Naruse T, Takechi M, Kamata N. Zoledronate inhibits receptor activator of nuclear factor kappa-B ligand-induced osteoclast differentiation via suppression of expression of nuclear factor of activated T-cell $\mathrm{c} 1$ and carbonic anhydrase 2. Arch Oral Biol. 2015;60:557-65. 